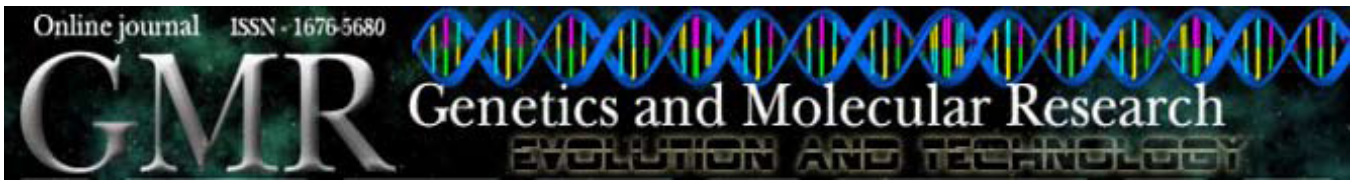

\title{
Up-regulation of Id1 in peripheral blood of psoriatic patients
}

\author{
C. Ronpirin ${ }^{1}$, M. Achariyakul ${ }^{2}$, T. Tencomnao ${ }^{3}$, J. Wongpiyabovorn ${ }^{4,5}$ and \\ W. Chaicumpa ${ }^{6}$ \\ ${ }^{1}$ Department of Preclinical Science, Faculty of Medicine, Thammasat University, \\ Pathumthani, Thailand \\ ${ }^{2}$ Department of Internal Medicine, Faculty of Medicine, Thammasat University, \\ Pathumthani, Thailand \\ ${ }^{3}$ Department of Clinical Chemistry, Faculty of Allied Health Sciences, \\ Center for Excellence in Omics-Nano Medical Technology Project Development, \\ Chulalongkorn University, Bangkok, Thailand \\ ${ }^{4}$ Department of Microbiology, Immunology Unit, Faculty of Medicine, \\ Chulalongkorn University, Bangkok, Thailand \\ ${ }^{5}$ Lupus Research Unit, Chulalongkorn University, Bangkok, Thailand \\ ${ }^{6}$ Department of Parasitology, Faculty of Medicine Siriraj Hospital, \\ Mahidol University, Bangkok, Thailand \\ Corresponding author: C. Ronpirin \\ E-mail: cronpirin@yahoo.com
}

Genet. Mol. Res. 9 (4): 2239-2247 (2010)

Received June 29, 2010

Accepted August 8, 2010

Published November 16, 2010

DOI 10.4238/vol9-4gmr963

ABSTRACT. Although the precise causes of psoriasis are unclear, it is widely accepted that psoriasis is a disorder in which factors in the immune system, enzymes, and other biochemical substances that regulate skin cell division are impaired, leading to rapid proliferation of keratinocytes and incomplete keratinization. Expression of the helix-loop-helix transcription factor Id1 (inhibitor of differentiation/DNA binding), functioning as an inhibitor of differentiation, is known to increase in psoriatic skin. However, the molecular involvement of this particular biomarker in the psoriatic immune system remains to be elucidated. We measured Idl mRNA expression in peripheral blood mononuclear cells (PBMCs) of psoriatic patients and healthy controls using semi-quantitative reverse transcriptase- 
PCR. The normalized level of Id1 transcripts in psoriatic patients was about 2-fold higher than that in controls $(\mathrm{P}<0.05)$. When we examined the proliferation rate of PBMCs, the stimulation index obtained from the phytohemagglutinin stimulation assay was not significantly different in psoriatic patients. In patients with psoriasis, there was no correlation between the stimulation index and the psoriasis area severity index. We suggest that Id1 has a role in causing psoriatic immune cell symptoms.

Key words: PBMCs; Psoriasis; Gene expression analysis; Proliferation; Id1; mRNA

\section{INTRODUCTION}

Psoriasis, affecting approximately $2-4 \%$ of the population worldwide, is a common immunologically mediated inflammatory and hyperproliferative disease of the skin and joints, with a multifactorial genetic basis (Henseler, 1998; Ronpirin and Tencomnao, 2010). In histopathology, mixed inflammatory infiltrates are observed, primarily consisting of lymphocytes and monocytes (Ackerman, 1978). In recent years, it has been revealed that psoriatic skin lesions respond to certain immunosuppressive agents such as methotrexate, cyclosporine and macrolide immunosuppressants (Jeffes et al., 1995; Ozawa et al., 1999; Marsland and Griffiths, 2002). Another frequently used treatment modality in psoriasis, referred to as phototherapy, targets principally immune cells located in the epidermis and dermis (Vallat et al., 1994). The role of activated lymphocytes and monocytes in the immunopathogenesis of psoriasis is now broadly acknowledged. Furthermore, it has been shown that lymphocyte activation in the peripheral blood plays a central part in the pathogenesis of psoriasis (Abrams et al., 2000). Taken together, psoriasis is regarded as a type $1 \mathrm{~T}$ cell (Th1)-associated disease, since alterations in cytokine production both locally and systemically have been demonstrated (Schön and Boehncke, 2005; Lowes et al., 2007). As a result, systematically administered anti-lymphocyte and anti-tumor necrosis factor alpha (TNF- $\alpha$ ) antibodies have been proven to provide impressive improvement of psoriasis (Krueger et al., 2000; Gottlieb et al., 1995, 2000, 2003; Kupper, 2003).

Because there is no known mechanism or disease process to explain psoriasis, several research groups have examined various genes as molecular markers responsible for the pathogenesis of psoriasis. The helix-loop-helix transcription factor Id1 (inhibitor of differentiation or inhibitor of DNA binding) has recently received much attention. It is a transcription factor that suppresses cell differentiation, but promotes cell proliferation and survival. Its expression was found in several cell types such as synovial tissues of patients with rheumatoid arthritis and tumor cells (Sakurai et al., 2001; Wong et al., 2004). Very interestingly, elevated Id1 gene expression was reported in keratinocytes of psoriatic patients' skin (Bjorntorp et al., 2003), and an activated Id 1 pathway was subsequently corroborated by another investigation (Mark et al., 2006), suggesting its molecular role in psoriasis.

However, Id1 expression status in psoriatic immune system, particularly peripheral blood lymphocytes and monocytes, has never been elucidated. In the present study, our objectives were to examine the expression of Id1 mRNA transcripts in peripheral blood mononuclear cells (PBMCs) of psoriatic patients, compared to healthy controls, and to investigate the role of Id1 expression with respect to proliferation of PBMCs as well as the correlation between severity of psoriasis and proliferation of PBMCs. 
Up-regulation of Id1 in peripheral blood of psoriatic patients

\section{MATERIAL AND METHODS}

\section{Blood samples}

Participants in the present study consisted of 15 Thai patients with psoriasis (mean age $\pm \mathrm{SD}=$ $56.133 \pm 13.93$ years) diagnosed clinically by an experienced dermatologist at Thammasat Chalermprakiat Hospital and 9 unrelated healthy Thai volunteers ( $35.56 \pm 8.88$ years) without a family history of psoriasis, recruited from the Faculty of Medicine, Thammasat University and the Faculty of Allied Health Sciences, Chulalongkorn University. All patients were free from any systemic skin therapies and/or phototherapy. The severity of psoriasis was classified according to European Medicines Agency Committee by the psoriasis area and severity index (PASI): $<10=$ mild, $10-20=$ moderate, $>20=$ severe (Naldi, 2010). The Ethics Committee of Medical Experiments on Human Subjects (Faculty of Medicine, Thammasat University) approved the study. Informed consent was obtained from all participants prior to inclusion in the study.

\section{Isolation of PBMCs}

PBMCs were isolated from $10 \mathrm{~mL}$ blood from each subject using standard Ficoll density gradient centrifugation. Subsequently, lymphocytes were subjected to further experiments: analysis of Id1 mRNA expression and lymphocyte proliferation assay.

\section{Total RNA extraction and semi-quantitative reverse transcriptase-polymerase chain reaction (RT-PCR)}

Total cellular RNA was isolated from lymphocytes using Trizol reagent (Invitrogen, Carlsbad, CA, USA), according to manufacturer instructions. The amount of RNA was determined by absorbance at $260 \mathrm{~nm}$. First-strand cDNA was synthesized from $200 \mathrm{ng}$ DNase I-treated RNA using the ImProm-IITM Reverse Transcription System (Promega, Madison, WI, USA) with oligo(dT)17 primer, following the manufacturer protocol. RT was carried out at $42^{\circ} \mathrm{C}$ for $60 \mathrm{~min}$. After cDNA synthesis, the desired DNA fragment was then amplified for 35 cycles using MasterTaq (Eppendorf, Hamburg, Germany) with specific primers for Id1 transcripts [sense primer: 5'-TTC AGC CAG TCG CCA AGA ATC-3' and anti-sense primer: 5'-GCG CTG ATC TCG CCG TTG AG-3'] (Ishiguro et al., 1996) and for glyceraldehyde-3-phosphate dehydrogenase (GAPDH) internal control transcripts [sense primer: 5'-GAA GGT GAA GGT CGG AGT C-3' and anti-sense primer: 5'-GAA GAT GGT GAT GGG ATT TC-3'] (Hu et al., 2004). Each cycle of PCR consisted of a 30-s denaturation at $94^{\circ} \mathrm{C}$, a 1-min annealing at $60^{\circ} \mathrm{C}$ for Id 1 or $58^{\circ} \mathrm{C}$ for GAPDH, and a 1 -min extension at $72^{\circ} \mathrm{C}$. The products of RT-PCR were resolved by $1.5 \%$ agarose gel electrophoresis and visualized by ethidium bromide staining. The DNA bands corresponding to Id1 and GAPDH transcripts were 434 and 226 bp, respectively. All band densities were analyzed by the 1D-Multi Lane Densitometry program in an AlphaImager 2000 (Alpha Innotech Corp., San Leandro, CA, USA). The Id1 density was normalized to GAPDH density.

\section{Cell proliferation assay}

PBMCs prepared from patients with psoriasis and healthy controls were evaluated for their proliferation rate using ${ }^{3} \mathrm{H}$-thymidine uptake. Briefly, cells were stimulated with $5 \mu \mathrm{g} / \mathrm{mL}$ phytohemagglutinin (PHA) for $72 \mathrm{~h}$ at $37^{\circ} \mathrm{C}$ in $5 \% \mathrm{CO}_{2}$. They were pulsed with $1 \mu \mathrm{Ci} / \mathrm{mL}^{3} \mathrm{H}$-methyl-thymi- 
dine $\left({ }^{3} \mathrm{H}-\mathrm{TdR}\right)$ during the last $6 \mathrm{~h}$ of incubation. After incubation, cells were harvested and ${ }^{3} \mathrm{H}-\mathrm{TdR}$ incorporation was measured using a scintillation counter (Packard Instruments, Downers Grove, IL, USA). The stimulation index (SI) was calculated as the ratio between counts per min obtained in the presence of PHA and that obtained without PHA. A positive response was considered as a difference between PHA-treated cells and untreated cells greater than 2000 and an SI greater than 5.

\section{Statistical analysis}

Each experiment was performed in triplicate. The data represented the mean $\pm \mathrm{SD}$ of three independent experiments and were analyzed by the Student $t$-test. The correlation coefficient was calculated using Pearson's correlation. Differences at $\mathrm{P}<0.05$ were considered to be significant.

\section{RESULTS}

Using semi-quantitative RT-PCR, expression of Id1 mRNA transcripts was found in both patients with psoriasis $(\mathrm{N}=7)$ and healthy controls $(\mathrm{N}=5)$ as shown in Figure 1A. Our semi-quantitative analysis demonstrated that Id1 mRNA expression in the psoriatic samples was approximately 2 -fold higher than in the control samples with regard to the normalized Id1 mRNA expression (Figure 1B). The difference in Id1 mRNA expression between the two groups was statistically significant $(\mathrm{P}<0.05)$.

A

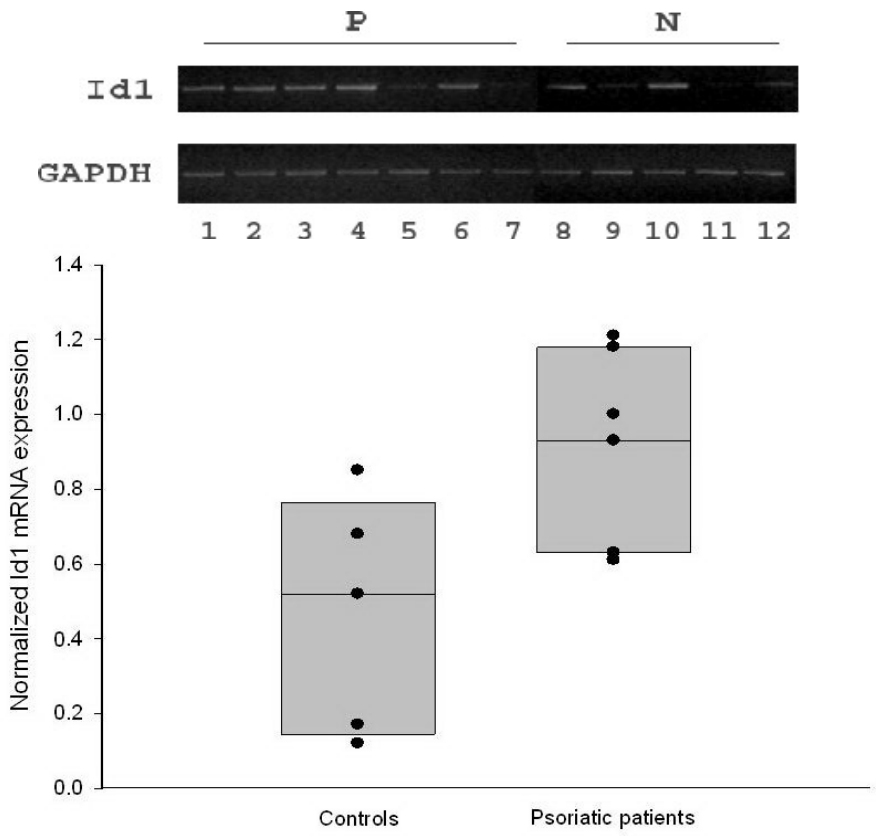

Figure 1. Expression of Id1 mRNA as detected by semi-quantitative reverse transcriptase-polymerase chain reaction (RT-PCR) in PBMCs isolated from normal controls and patients with psoriasis. A. 1.5\% agarose gel electrophoresis (P; lanes 1-7) and normal controls (N; lanes 8-12). B. Box plot showing normalized Id1 mRNA expression, comparing the two groups. Id1 = inhibitor of differentiation or inhibitor of DNA binding; GAPDH = glyceraldehyde-3-phosphate dehydrogenase. 
Using ${ }^{3} \mathrm{H}$-thymidine uptake, PBMCs prepared from normal controls $(\mathrm{N}=9)$ and patients with psoriasis $(\mathrm{N}=15)$ were analyzed for their proliferation rate. All PBMCs of controls had a positive response as clearly shown by SI, whereas one patient with psoriasis had a negative response $(\mathrm{SI}=2)$. Nonetheless, no difference between the two groups was found with respect to the proliferation of PBMCs $(\mathrm{P}>0.05)$ as demonstrated in Figure 2.

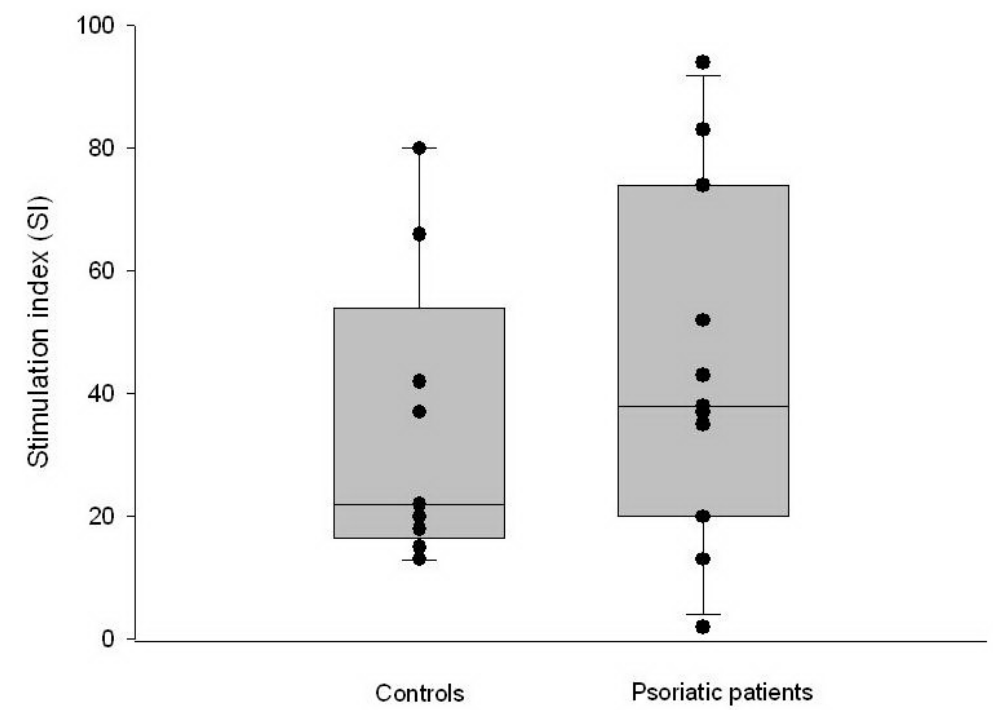

Figure 2. Box plot showing stimulation index (SI) as proliferation of PBMCs isolated from normal controls and patients with psoriasis, determined by ${ }^{3} \mathrm{H}$-thymidine uptake.

We were able to determine the correlation between PASI score and SI with respect to patients with psoriasis $(\mathrm{N}=15)$, since patient characteristics with clinical data recorded at the time of enrollment and resulting experimental data were available with regard to each patient, which were put together as shown in Table 1. Using Pearson's correlation as an analytical tool, no correlation between PASI score and SI was found $(\mathrm{P}>0.05)$, as depicted in Figure 3.

\begin{tabular}{|c|c|c|c|c|c|c|}
\hline Patient No. & Gender & $\begin{array}{c}\text { Age } \\
\text { (years) }\end{array}$ & $\begin{array}{c}\text { Age at onset of } \\
\text { symptoms (years) }\end{array}$ & $\begin{array}{c}\text { Most recent psoriatic lesions } \\
\text { observed prior to enrollment (months) }\end{array}$ & $\begin{array}{l}\text { Stimulation } \\
\text { index (SI) }\end{array}$ & $\begin{array}{l}\text { PASI } \\
\text { score }\end{array}$ \\
\hline 1 & Female & 65 & 24 & 12 & 74 & 3.4 \\
\hline 2 & Male & 25 & 14 & 1 & 35 & 1.9 \\
\hline 3 & Male & 72 & 71 & 2 & 2 & 1.6 \\
\hline 4 & Female & 53 & 48 & 3 & 43 & 1.8 \\
\hline 5 & Female & 47 & 30 & 12 & 94 & 5.9 \\
\hline 6 & Female & 53 & 34 & 24 & 83 & 4.5 \\
\hline 7 & Female & 58 & 20 & 60 & 52 & 11.9 \\
\hline 8 & Female & 63 & 58 & 24 & 38 & 1.8 \\
\hline 9 & Male & 68 & 66 & 1 & 13 & 6.6 \\
\hline 10 & Male & 75 & 70 & 6 & 20 & 2.3 \\
\hline 11 & Female & 58 & 39 & 2 & 37 & 4.3 \\
\hline 12 & Female & 37 & 31 & 12 & 37 & 0.3 \\
\hline 13 & Male & 69 & 36 & 12 & 23 & 2.2 \\
\hline 14 & Male & 41 & 25 & 12 & 14 & 5.2 \\
\hline 15 & Male & 58 & 35 & 12 & 15 & 1.2 \\
\hline
\end{tabular}

PASI $=$ psoriasis area and severity index. 


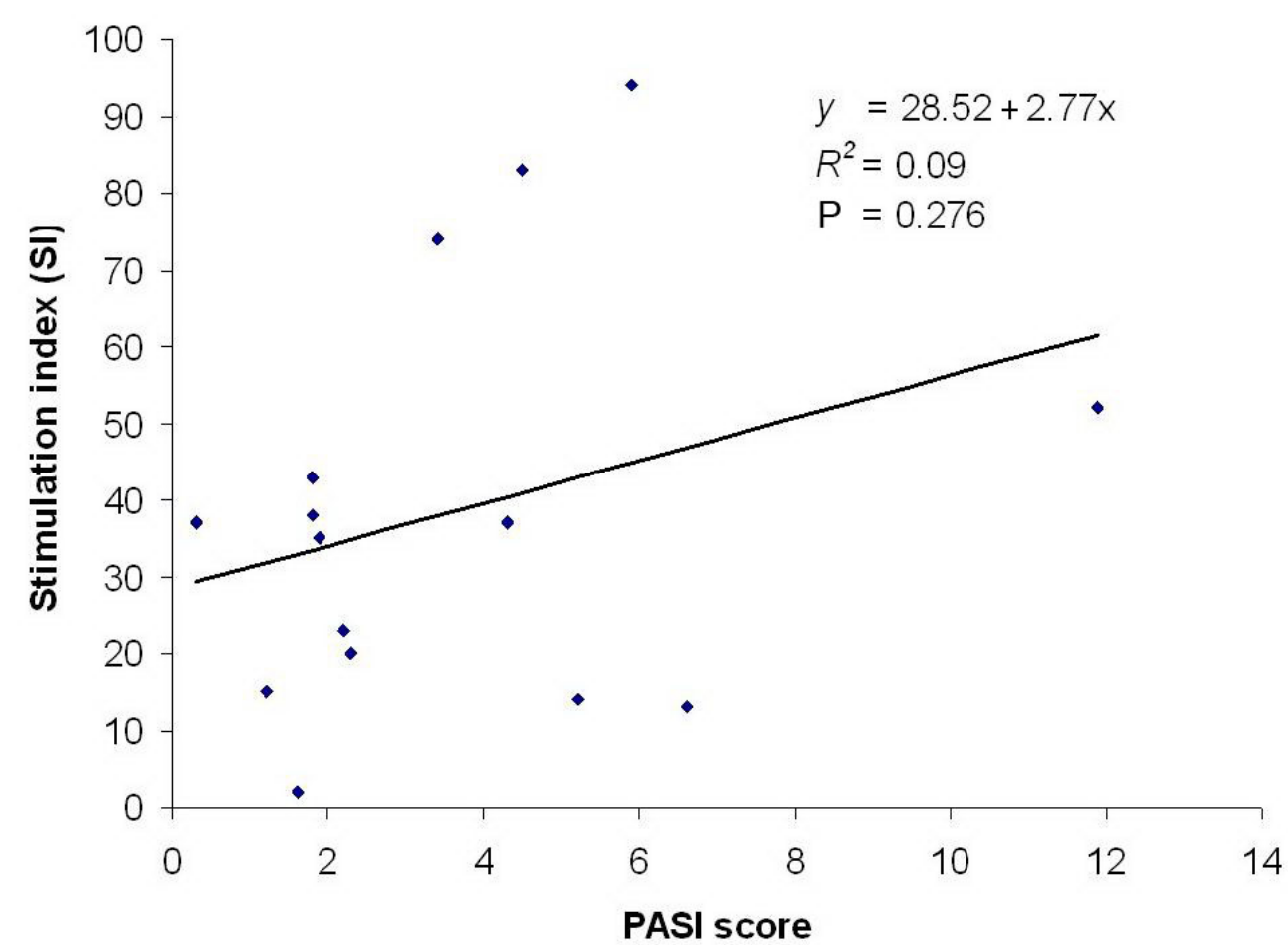

Figure 3. Pearson's correlation between psoriasis area and severity index (PASI) score ( $y$ represents linear regression equation; $R^{2}$ represents correlation coefficient).

\section{DISCUSSION}

Patients enrolled in this study were mainly classified as having mild psoriasis since their PASI scores were less than 10 . There was only one patient with moderate psoriasis (PASI $=11.9$ ). Nevertheless, for the first time, about 2-fold higher expression of Id1 mRNA transcripts in PBMCs was found in the patient group compared to the control group $(\mathrm{P}<0.05)$, as detected by semiquantitative RT-PCR. Our finding was in agreement with the previously reported up-regulation of Id1 mRNA transcripts in keratinocytes of psoriatic involved skin as compared to uninvolved skin from the same patients and to skin from normal controls (Bjorntorp et al., 2003; Mark et al., 2006).

As far as human cells are concerned, it has been demonstrated that Id genes are expressed in human acute myelogenous leukemia cells, and that knockdown of Id1 expression inhibits leukemic cell growth in vitro, suggesting that Id1 is required for leukemic cell proliferation (Suh et al., 2008). Id1 has been shown to be a common downstream target of tyrosine kinases in leukemic cells, thus making it a potential therapeutic target for leukemias (Tam et al., 2008). Regarding a signaling cascade, it should be noted that the induction of protein tyrosine kinases is known to be a key element in the activation of lymphocytes. In particular, tyrosine phosphorylation in psoriatic $\mathrm{T}$ cells has been demonstrated to be modulated by drugs that induce or improve psoriasis (Ockenfels et al., 1995). Therefore, our present finding, up-regulation of Id1 gene expression in psoriatic PBMCs, may also be due to a molecular 
mechanism via the tyrosine kinase signaling pathway. However, this speculation should be experimentally proven in the future study.

It has been shown using a T-cell line model that Id1 expression stimulates baseline levels

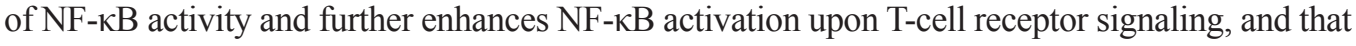
Id1-potentiated activation of NF- $\mathrm{KB}$ leads to overproduction of cytokines such as TNF- $\alpha$ and interferon gamma (IFN- $\gamma$ ) in a T-cell line as well as in thymocytes (Yang et al., 2006). Since it has been well documented that an increase in cytokine levels produced by Th1 cells, including TNF- $\alpha$ and IFN- $\gamma$, is observed in lesional T lymphocytes and circulating T lymphocytes of patients with psoriasis (Ettehadi et al., 1994; Bonifati et al., 1994; Prinz et al., 1994; Vollmer et al., 1994; Bata-Csorgo et al., 1995a,b; Szabo et al., 1998; Austin et al., 1999; Friedrich et al., 2000), the overexpression of these cytokines may occur as a result of Id1-potentiated activation of NF$\kappa \mathrm{B}$. Interestingly, a recent genome-wide scan further emphasized the role of the NF- $\mathrm{B}$ pathway in psoriasis (Nair et al., 2009). The molecular connections between Id1, NF- $\mathrm{KB}$ and cytokine production in psoriatic PBMCs will therefore be of great interest to investigate in the near future.

Since Id 1 expression has been primarily found in lymphocytes in a proliferative state (Rivera and Murre, 2001), "psoriatic patients' PBMCs having greater proliferative potential" was our other hypothesis in the present investigation. Based on the PHA stimulation assay, the two groups showed no difference in cell proliferation as reflected by SI. There was only one patient with psoriasis whose PBMCs did not respond well to PHA. This might have been due to certain factors such as elderly age and disease associated with a defect in cell-mediated immunity. In addition, we found no correlation between PASI score and SI, implying that SI can not be used as an indicator of disease severity with regard to psoriasis.

Because psoriasis is a chronic and recurrent inflammatory skin disease, patients with psoriasis are likely to have a rise in leukocytes, primarily neutrophils (Rocha-Pereira et al., 2004). However, our recent investigation revealed an increase in lymphocytes in psoriatic patients as compared to those of healthy controls (Ketboonlue, 2007), which was in accordance with previous reports by others (Rocha-Pereira et al., 2004; Böhm, 2006), thereby supporting the notion of PBMCs as attention-grabbing targets in the present study.

In conclusion, our semi-quantitative RT-PCR results in the present study demonstrate over-expression of Id1 mRNA transcripts in PBMCs of patients with psoriasis as compared to those of healthy controls, whereas there is no difference in immune response between the two groups as determined using the PHA non-specific cell-mediated immunity stimulation test. This finding may provide a novel insight into the pathogenesis of this disease as well as indicating a potential therapeutic target. Nevertheless, further studies should be conducted to investigate the regulation of Id1 in immunopathogenesis and its therapeutic potential in psoriasis, e.g., is the therapeutic effect of systematically administered anti-psoriatic drugs linked to suppression of Id1? It would also be of great interest to define target genes and binding partners for Id1 in immune cells during the pathogenesis of this disease.

\section{ACKNOWLEDGMENTS}

Research supported by a TRF-CHE research grant for new scholar (\#MRG4880147). We gratefully acknowledge the active participation of healthy controls and patients with psoriasis. Also, we would like to thank Ms. Phantipa Protjaroen for her excellent technical assistance. 


\section{REFERENCES}

Abrams JR, Kelley SL, Hayes E, Kikuchi T, et al. (2000). Blockade of T lymphocyte costimulation with cytotoxic T lymphocyte-associated antigen 4-immunoglobulin (CTLA4Ig) reverses the cellular pathology of psoriatic plaques, including the activation of keratinocytes, dendritic cells, and endothelial cells. J. Exp. Med. 192: 681-694.

Ackerman AB (1978). Psoriasis. In: Histologic Diagnosis of Inflammatory Skin Diseases (Ackerman AB, ed.). Lea and Febiger, Philadelphia, 251-256.

Austin LM, Ozawa M, Kikuchi T, Walters IB, et al. (1999). The majority of epidermal T cells in Psoriasis vulgaris lesions can produce type 1 cytokines, interferon-gamma, interleukin-2, and tumor necrosis factor-alpha, defining TC1 (cytotoxic T lymphocyte) and TH1 effector populations: a type 1 differentiation bias is also measured in circulating blood T cells in psoriatic patients. J. Invest. Dermatol. 113: 752-759.

Bata-Csorgo Z, Hammerberg C, Voorhees JJ and Cooper KD (1995a). Intralesional T-lymphocyte activation as a mediator of psoriatic epidermal hyperplasia. J. Invest. Dermatol. 105: 89S-94S.

Bata-Csorgo Z, Hammerberg C, Voorhees JJ and Cooper KD (1995b). Kinetics and regulation of human keratinocyte stem cell growth in short-term primary ex vivo culture. Cooperative growth factors from psoriatic lesional T lymphocytes stimulate proliferation among psoriatic uninvolved, but not normal, stem keratinocytes. J. Clin. Invest. 95: 317-327.

Bjorntorp E, Parsa R, Thornemo M, Wennberg AM, et al. (2003). The helix-loop-helix transcription factor Id1 is highly expressed in psoriatic involved skin. Acta Derm. Venereol. 83: 403-409.

Böhm I (2006). Quantification of absolute peripheral white blood cells and their subsets in patients with lupus erythematosus: comparison with other inflammatory diseases with and without autoimmune background. Biomed. Pharmacother. 60: 92-95.

Bonifati C, Carducci M, Cordiali FP, Trento E, et al. (1994). Correlated increases of tumour necrosis factor-alpha, interleukin-6 and granulocyte monocyte-colony stimulating factor levels in suction blister fluids and sera of psoriatic patients - relationships with disease severity. Clin. Exp. Dermatol. 19: 383-387.

Ettehadi P, Greaves MW, Wallach D, Aderka D, et al. (1994). Elevated tumour necrosis factor-alpha (TNF-alpha) biological activity in psoriatic skin lesions. Clin. Exp. Immunol. 96: 146-151.

Friedrich M, Krammig S, Henze M, Docke WD, et al. (2000). Flow cytometric characterization of lesional T cells in psoriasis: intracellular cytokine and surface antigen expression indicates an activated, memory/effector type 1 immunophenotype. Arch. Dermatol. Res. 292: 519-521.

Gottlieb AB, Lebwohl M, Shirin S, Sherr A, et al. (2000). Anti-CD4 monoclonal antibody treatment of moderate to severe psoriasis vulgaris: results of a pilot, multicenter, multiple-dose, placebo-controlled study. J. Am. Acad. Dermatol. 43: 595-604.

Gottlieb AB, Masud S, Ramamurthi R, Abdulghani A, et al. (2003). Pharmacodynamic and pharmacokinetic response to anti-tumor necrosis factor-alpha monoclonal antibody (infliximab) treatment of moderate to severe psoriasis vulgaris. J. Am. Acad. Dermatol. 48: 68-75.

Gottlieb SL, Gilleaudeau P, Johnson R, Estes L, et al. (1995). Response of psoriasis to a lymphocyte-selective toxin (DAB389IL-2) suggests a primary immune, but not keratinocyte, pathogenic basis. Nat. Med. 1: 442-447.

Henseler T (1998). Genetics of psoriasis. Arch. Dermatol. Res. 290: 463-476.

Hu LH, Chen FH, Li YR and Wang L (2004). Real-time determination of human telomerase reverse transcriptase mRNA in gastric cancer. World J. Gastroenterol. 10: 3514-3517.

Ishiguro A, Spirin KS, Shiohara M, Tobler A, et al. (1996). Id2 expression increases with differentiation of human myeloid cells. Blood 87: 5225-5231.

Jeffes EW III, McCullough JL, Pittelkow MR, McCormick A, et al. (1995). Methotrexate therapy of psoriasis: differential sensitivity of proliferating lymphoid and epithelial cells to the cytotoxic and growth-inhibitory effects of methotrexate. J. Invest. Dermatol. 104: 183-188.

Ketboonlue K (2007). Detection of Serotonin and Development of Laboratory Technique for Detecting Autoantibodies to Serotonin in the Psoriatic Patients' Blood. Master's thesis, Chulalongkorn University, Bangkok.

Krueger JG, Walters IB, Miyazawa M, Gilleaudeau P, et al. (2000). Successful in vivo blockade of CD25 (high-affinity interleukin 2 receptor) on T cells by administration of humanized anti-Tac antibody to patients with psoriasis. J. Am. Acad. Dermatol. 43: 448-458.

Kupper TS (2003). Immunologic targets in psoriasis. N. Engl. J. Med. 349: 1987-1990.

Lowes MA, Bowcock AM and Krueger JG (2007). Pathogenesis and therapy of psoriasis. Nature 445: 866-873.

Mark EB, Jonsson M, Asp J, Wennberg AM, et al. (2006). Expression of genes involved in the regulation of p16 in psoriatic involved skin. Arch. Dermatol. Res. 297: 459-467.

Marsland AM and Griffiths CE (2002). The macrolide immunosuppressants in dermatology: mechanisms of action. Eur.

Genetics and Molecular Research 9 (4): 2239-2247 (2010)

CFUNPEC-RP www.funpecrp.com.br 
J. Dermatol. 12: 618-622.

Nair RP, Duffin KC, Helms C, Ding J, et al. (2009). Genome-wide scan reveals association of psoriasis with IL-23 and NF-kappaB pathways. Nat. Genet. 41: 199-204.

Naldi L (2010). Scoring and monitoring the severity of psoriasis. What is the preferred method? What is the ideal method? Is PASI passe? Facts and controversies. Clin. Dermatol. 28: 67-72.

Ockenfels HM, Nussbaum G, Schultewolter T, Mertins K, et al. (1995). Tyrosine phosphorylation in psoriatic T cells is modulated by drugs that induce or improve psoriasis. Dermatology 191: 217-225.

Ozawa A, Sugai J, Ohkido M, Ohtsuki M, et al. (1999). Cyclosporin in psoriasis: continuous monotherapy versus intermittent long-term therapy. Eur. J. Dermatol. 9: 218-223.

Prinz JC, Gross B, Vollmer S, Trommler P, et al. (1994). T cell clones from psoriasis skin lesions can promote keratinocyte proliferation in vitro via secreted products. Eur. J. Immunol. 24: 593-598.

Rivera R and Murre C (2001). The regulation and function of the Id proteins in lymphocyte development. Oncogene 20: 8308-8316.

Rocha-Pereira P, Santos-Silva A, Rebelo I, Figneiredo A, et al. (2004). Erythrocyte damage in mild and severe psoriasis. Br. J. Dermatol. 150: 232-244.

Ronpirin C and Tencomnao T (2010). Psoriasis: A review of the role of serotonergic system. Afr. J. Biotechnol. 9: 15281534.

Sakurai D, Yamaguchi A, Tsuchiya N, Yamamoto K, et al. (2001). Expression of ID family genes in the synovia from patients with rheumatoid arthritis. Biochem. Biophys. Res. Commun. 284: 436-442.

Schön MP and Boehncke WH (2005). Psoriasis. N. Engl. J. Med. 352: 1899-1912.

Suh HC, Leeanansaksiri W, Ji M, Klarmann KD, et al. (2008). Id1 immortalizes hematopoietic progenitors in vitro and promotes a myeloproliferative disease in vivo. Oncogene 27: 5612-5623.

Szabo SK, Hammerberg C, Yoshida Y, Bata-Csorgo Z, et al. (1998). Identification and quantitation of interferon-gamma producing T cells in psoriatic lesions: localization to both CD4+ and CD8+ subsets. J. Invest. Dermatol. 111: $1072-$ 1078.

Tam WF, Gu TL, Chen J, Lee BH, et al. (2008). Id1 is a common downstream target of oncogenic tyrosine kinases in leukemic cells. Blood 112: 1981-1992.

Vallat VP, Gilleaudeau P, Battat L, Wolfe J, et al. (1994). PUVA bath therapy strongly suppresses immunological and epidermal activation in psoriasis: a possible cellular basis for remittive therapy. J. Exp. Med. 180: 283-296.

Vollmer S, Menssen A, Trommler P, Schendel D, et al. (1994). T lymphocytes derived from skin lesions of patients with psoriasis vulgaris express a novel cytokine pattern that is distinct from that of $\mathrm{T}$ helper type 1 and $\mathrm{T}$ helper type 2 cells. Eur. J. Immunol. 24: 2377-2382.

Wong YC, Wang X and Ling MT (2004). Id-1 expression and cell survival. Apoptosis 9: 279-289.

Yang Y, Liou HC and Sun XH (2006). Id1 potentiates NF-kappaB activation upon T cell receptor signaling. J. Biol. Chem. 281: 34989-34996. 